\title{
Introduction: Review Symposium on Morton's Moving Up without Losing Your Way
}

\author{
Tomas de Rezende Rocha ${ }^{1}$
}

Accepted: 3 February 2021 / Published online: 23 June 2021

(c) The Author(s), under exclusive licence to Springer Nature B.V. 2021

The celebrated Mexican author Carlos Fuentes once had a character proudly proclaim: "Yo no soy mexicano. Yo no soy gringo. Yo soy chicano. No soy gringo en USA y mexicano en México. Soy chicano en todas partes. No tengo que asimilarme a nada" (1995, p. 329). "I am Chicano everywhere," he asserts. "I don't have to assimilate to anything." And indeed, why should he? Pride has various functions, after all, one of which is to be a shield against the stifling demands of majoritarian conformity. This type of pride is a comforting, empowering reminder of belonging and originality. For all its usefulness, however, pride in one's place of origin cannot inoculate the average immigrant from the longing she feels for the loved ones she has left behind. It will not remove the stumbling blocks that get in the way of navigating life in a new country, with its unfamiliar social mores that may alienate and depress. And pride is no replacement for the fluency of language and culture in one's home community that begins to deteriorate as soon as one steps on new soil. The immigrant may gain opportunities, yes, but often at great cost to herself and her community: the friends, family, and fellow denizens she cannot take with her, and who in turn may well suffer in her absence.

As it is with many immigrants, so it is with 'strivers', the social group examined by Jennifer M. Morton in her most recent book, Moving Up without Losing Your Way: The Ethical Costs of Upward Mobility (Princeton University Press, 2019a). With characteristic care and lucidity, Morton here continues a long-standing intellectual project dedicated to revealing the myriad ways we undermine, ignore, and disrespect the flourishing and practical reasoning of the oppressed. Strivers, for Morton, are people who seek a better life for themselves, typically by pursuing higher education, and often by enmeshing themselves in different communities, "those in which opportunities for advancement are available" (p. 7). As I did in the paragraph above, Morton leans into the immigrant analogy to explain some of the core features of being a striver, while noting that these two groups do not perfectly overlap. As she explains in her response to the four reviews included in this symposium, the term 'striver' is reserved to describe those low-income and (often) first-generation students who, in the pursuit of upward mobility, are "caught between pursuing their educational and career opportunities and remaining closely tied to their family, friends, and community." The deterioration of these valuable and meaningful bonds, which Morton calls "ethical goods," are the "ethical costs" of striving. Students from all backgrounds may

Tomas de Rezende Rocha

trocha@uw.edu

1 UW College of Education, Social \& Cultural Foundations, Seattle, USA 
confront these ethical costs at some point or another, but strivers are uniquely vulnerable to them given their unjust background conditions.

Morton's treatment of the plight of the striver so interested the membership of the North Eastern Philosophy of Education Society (NEPES) that we voted-in the middle of an extraordinarily difficult year marked by a global pandemic, uprisings against racist policing, and further corruption of democratic norms and institutions- to select it as the focus of a summer reading group. Over a period of three weeks in June 2020, NEPES hosted three discussions of Morton's book for 18 of our members. During each session, we spent time discussing in broad strokes the chapters for that week and then divided into virtual rooms with colleagues old and new to contemplate the text with the care afforded by more intimate spaces. (There aren't too many professional philosophers of education out there, and we tend to be dispersed across separate colleges and faculties of education, so it is a rare and precious opportunity whenever we can read and discuss something together.) Most generously, Morton agreed to join us during the third and final session for a fun and productive Q\&A. Out of these sessions emerged the idea to harness our thinking by creating a symposium of reviews. With the approval of Studies in Philosophy and Education book review editor Petra Mikulan, we got underway.

I would like to thank Vik Joshi (Columbia University), Anna Dempsey (UMASS-Dartmouth), Alaina Gostomski (Independent Scholar), Garry Mitchell (Harvard University), Cara Furman (University of Maine-Farmington), and Dustin Webster (University of Pennsylvania) for their dedicated time and attention in developing four reviews to provoke Morton's thinking. The majority of these six reviewers are self-identified 'strivers' and/or from immigrant backgrounds, three of whom are current doctoral students in 'elite' universities. In organizing this symposium, we felt it would be particularly valuable to give priority to authors who, like Morton, could speak to her concerns from the 'inside'. While unanimously sympathetic to the work overall, the reviewers together draw three lines of critique along which Morton organizes her response.

First, it is possible that Morton conflates at least some ethical costs faced by all students in economic precarity with ethical costs that result from threats to the chosen values of particular students. Some strivers may face ethical costs due to their unjust background conditions, but perhaps it isn't always clear why this is a result mostly of their shared background rather than their good but ultimately optional values (e.g., community-driven values). Alternatively, if strivers' interdependent and community-driven values aren't quite optional but constitutive of who they are in a very deep way, might not Morton's framing of the account - addressed to strivers as individuals - reinforce just the kind of individualism she seeks to undermine? Second, it is possible that recognition of the unjust background conditions of strivers creates an obligation to directly dismantle those conditions rather than to focus on what Morton calls a "clear-eyed ethical narrative" of them (p. 121). As Morton suggests, we can surely do a better job of directing strivers through the halls of higher education and into the rooms where the levers of power reside. But making it easier for strivers to become upwardly mobile is no guarantee they will make things better for their home communities. As Morton herself argues elsewhere, at least some colleges and universities might have the opposite effect and "push members of marginalized communities who are educated in such institutions to become more like their privileged peers, undermining their capacity to diversify the elite" (2019b, p. 2). Further, when should an over-powered 'elite' educational institution (or the 'elite' itself, for that matter) be abolished altogether rather than merely diversified? Third, it is not just college-age students but young children who are put in the position of 'striving', often by teachers and caregivers who fearfully block children from relationships that would keep them more securely fastened to their home 
communities. Given that children are in such an early and delicate stage of learning how to form, revise, and pursue their conceptions of a good life, aren't parents and families a more appropriate audience for the ideas and concerns explored by Morton? I will leave it up to the reader to both sort through the details of the reviewers' comments and enjoy Morton's thoughtful response.

Thanks again to Jennifer Morton as author and to Joshi, Dempsey, Gostomski, Mitchell, Furman, and Webster as critics. Special thanks to NEPES President Cara Furman, the NEPES Executive Board, Petra Mikulan, and Studies in Philosophy and Education for collaborating on a fruitful symposium. Finally, thanks to all 18 members of the 2020 NEPES reading group.

\section{References}

Fuentes, C. 1995. La frontera de cristal: Una novela en nueve cuentos. London: Alfaguara.

Morton, J. 2019a. Moving up without losing your way: The ethical costs of upward mobility. Princeton: Princeton University Press.

Morton, J. 2019b. The miseducation of the elite. The Journal of Political Philosophy 2: 1-22.

Publisher's Note Springer Nature remains neutral with regard to jurisdictional claims in published maps and institutional affiliations. 